\title{
0 processo aterosclerótico em artérias de coelhos submetidos a dieta suplementada com gema de ovo: modelo experimental de baixo custo
}

\author{
Atherosclerotic lesion formation in rabbits fed on egg yolk-supplemented diet: \\ an inexpensive experimental model
}

\author{
Rodrigo Gibin Jaldin¹, H ênio Arruda Falcão Filho' ${ }^{1}$, Júlio Lopes Sequeira², W inston Bonetti Yoshida ${ }^{3}$
}

\section{Resumo}

O bjetivo: Verificar a aterogenicidade do modelo de hipercolesterolemia por suplementação alimentar com gema de ovo em coelhos e seu uso como modelo de aterosclerose experimental de

Material e método: Foram utilizados 14 coel hos divididos em dois grupos de sete animais: grupo controle $(G 1)$, que recebeu ração comercial ad libitum, e grupo tratado (G2), que foi alimentado com dieta suplementada com gema de ovo. Ambos os grupos foram alimentados por 90 dias. Foram realizadas dosagens do perfil lipídico dos animais nos momentos $0,30,60$ e 90 dias. Ao término do período experimental, os animais foram submetidos a eutanásia e retirada da aorta e de seus ramos diretos para realização de estudo anatomopatológico.

Resultados: Apenas no grupo $G 2$ houve aumento significativo nos níveis de colesterol total e frações. Ao exame macroscópico, foram observadas estrias gordurosas no arco aórtico e aorta abdominal e, à microscopia, acúmulos lipídicos discretos na íntima da aorta abdominal, renal, carótida, transição toracoabdominal e femoral. Portanto, a dieta com gema de ovo provocou aterosclerose leve no animal de experimentação e alterações equivalentes àquel as provocadas pelo colesterol purificado comercial quando fornecido em baixa dosagem. Assim sendo, a gema de ovo pode ser utilizada como fonte de colesterol alimentar de baixo custo em modelos de aterosclerose experimental.

Palavras-chave: Aterosclerose, colesterol, aorta, coelhos, dieta, dislipidemias. baixo custo.

\begin{abstract}
O bjective: To observe whether an inexpensive dietary-induced hypercholesterolemia model in rabbits using a chow diet supplemented with egg yolks can be used to develop atherosclerotic lesions in animals.

$M$ aterial and method: Fourteen rabbits were divided into two groups of seven animals: control group (G1), in which the rabbits were fed standard chow diet; and experimental group (G2), in which the rabbits were fed standard chow supplemented with egg yolks. Both groups were fed for 90 days. The lipid profile of all animals was measured at 0, 30, 60 and 90 days. At the end of the experimental period, euthanasia was performed and the aorta and its direct branches were excised to perform the histopathological examination.

Results: Therewas a significant increase in plasmatotal cholesterol and cholesterol fractions only in group G 2. The macroscopic examination showed fatty streaks in the aortic arch and abdominal aorta. $\mathrm{H}$ istological analyses revealed minimal lesions consisting of macrophages foam cells in the abdominal, renal, carotid and diaphragmatic aorta and femoral arteries. Therefore, the egg yolk diet developed mild atherosclerosis in rabbits and induced the same characteristics and extent of the lesions obtained by low-dosage purified cholesterol. Thus, egg yolk can be used as an inexpensive source of cholesterol in models of experimental atherosclerosis.
\end{abstract}

Keywords: Atherosclerosis, cholesterol, aorta, rabbits, diet, dyslipidemias.

\section{Introdução}

A aterosclerose é a principal causa de morte e Universidade Estadual Paulista (UNESP), Botucatu, SP.

2. Doutor. Professor assistente, Disciplina de Patologia Veterinária, Faculdade de Medicina Veterinária e Zootecnia (FMVZ), UNESP, Botucatu, SP.

3. Professor adjunto livre-docente, Disciplina de Cirurgia Vascular, Departamento de Cirurgia e Ortopedia, FMB, UNESP, Botucatu, SP

Artigo submetido em 12.09.06, aceito em 14.12.06. ncapacitação nos países ocidentais ${ }^{1,2}$. Consiste em processo crônico, progressivo esistêmico, caracterizado por resposta inflamatória e fibroproliferativa da parede arterial, a qual é causada por agressões à superfície arterial ${ }^{2}$. 0 distúrbio da função do en dotélio vascular é passo inicial para aterogênese ${ }^{3-5}$, sendo a hipercoleste- 
rolemia um dos seus principais desencadeantes ${ }^{6}$. A lesão aterosclerótica pode acometer vários e importantes territórios arteriais, sendo responsável por $95 \%$ das coronariopatias, $85 \%$ das claudicações intermitentes dosmembrosinferiores e $75 \%$ dos acidentes vasculares encefálicos ${ }^{7}$, além de ser um fator importanteno desenvolvimento do aneurisma de aorta abdominal ${ }^{8}$.

Frenteà importância dessa doença para o ser humano, houve, por parte dos pesquisadores, uma busca incessante de modelos experimentais que pudessem melhor caracterizá-la. Com a descoberta de que uma dieta rica em colesterol, por si só, era aterogênica, as atenções voltaram-se para model os baseados em suplementação com colesterol purificado e perdeu-se o interesse em pesquisar dietas compostas por outros elementos indutores de aterosclerose experimental, como proteínas animal e vegetal ${ }^{9,10}$. Em levantamento sobre as características dos métodos empregados em aterosclerose experimental, verificou-se que o coel ho éa espécie mais estudada equea hipercolesterolemia alimentar éa via mais prática de sua indução ${ }^{11}$.

Tem-se induzido aterosclerose em coelhos através do fornecimento de ração contendo $1 \%$ de colesterol por aproximadamente 12 semanas $^{12,13}$. Esse método permite não apenas a formação de lesões ateroscleróticas nas aortas torácica eabdominal ${ }^{12,13}$, como também se mostrou efetivo no estudo da aterosclerose carotídea em coelhos ${ }^{14}$. Bocan et al. forneceram a coelhos uma dieta composta por níveis variáveis de colesterol, mostrando que a extensão e o tipo de lesão aterosclerótica eram proporcionais à concentração de colesterol plasmático, o qual, por sua vez, aumentava de acordo com a porcentagem de colesterol na dieta ${ }^{15}$. Entretanto, 0 colesterol purificado disponível no mercado tem alto custo, o que limita seu amplo emprego no estudo da aterosclerose experimental (T abela 1).

Aslesões ateroscleróticasficam aparentementemais evidentes associando-se colesterol, gorduras saturadas e proteínas animais, produtos estes presentes e abundantes na gema de ovo. Em estudos prévios realizados em nosso laboratório, verificou-se significativo aumento na concentração de colesterol plasmático de coelhos alimentados com ração suplementada com gema de ovo ${ }^{16}$. A sobrecarga de colesterol através da gema de ovo, embora seja um model o pioneiro de aterosclerose experimental, não teve avaliação sistemática da distribuição eda intensidade do comprometimento vascular. Por conseguinte, propõe-seavaliar sea dieta em questão induz aterosclerose de maneira eficaz nas principais artérias do animal de experimentação (aorta, carótidas, renais, ilíacas comuns e femorais) e se pode ser usada como modelo experimental de baixo custo.

T abela 1 - C usto comparado entre suplemento de colesterol para a ração e a gema de ovo (di eta a 0,15\% de colesterol, para sete coelhos/dia, durante o período de 12 semanas)

\begin{tabular}{|c|c|c|c|c|c|c|}
\hline $\begin{array}{l}\text { Fonte de } \\
\text { colesterol }\end{array}$ & $\begin{array}{c}\% \text { de } \\
\text { colesterol }\end{array}$ & $\begin{array}{c}\text { T otal de } \\
\text { colesterol (G) } \\
\text { - } 3 \text { meses }\end{array}$ & $\begin{array}{c}\text { C usto } \\
\text { por grama }\end{array}$ & $\begin{array}{l}\text { Custo } \\
\text { por dia }\end{array}$ & $\begin{array}{c}\text { C usto } \\
\text { em US \$ \$ }\end{array}$ & $\begin{array}{l}\text { Custo } \\
\text { em R\$ }\end{array}$ \\
\hline $\begin{array}{l}\text { Cholesterol - 99\%, } \\
\text { porcineliver, } \\
\text { powder, grade I }\end{array}$ & $\begin{array}{c}0,15 \% \text { dieta = } \\
225 \mathrm{mg} / 150 \mathrm{~g} \\
\text { de ração }\end{array}$ & $141,75 \mathrm{~g}$ & $\begin{array}{c}1 \mathrm{~g}=U S \$ 36,00 \\
5 \mathrm{~g}=U S \$ 114,00 \\
25 \mathrm{~g}=U S \$ 315,00^{\dagger}\end{array}$ & $\begin{array}{c}\text { 1,575 g/dia } \\
\text { US\$ 19,85 } \\
\text { (frasco c/ } 25 \mathrm{~g} \text { ) }\end{array}$ & $1.786,50$ & $4.075,00$ \\
\hline $\begin{array}{l}\text { G ema de ovo } \\
\text { (uma gema contém } \\
\text { em média } 225 \text { mg } \\
\text { de colesterol) * }\end{array}$ & $\begin{array}{c}0,15 \% \text { dieta } \\
=1 \text { gema } / 150 \mathrm{~g} \\
\text { de ração }\end{array}$ & $\begin{array}{l}630 \text { ovos } \\
\text { (gemas) }\end{array}$ & $\begin{array}{c}30 \text { dúzias de } \\
\text { ovos }(81 \mathrm{~g} \text { col })= \\
\mathrm{R} \$ 27,98 \neq \\
: 1 \mathrm{~g}=\mathrm{R} \$ 0,35\end{array}$ & $\begin{array}{c}7 \text { ovos/dia } \\
\text { (gemas) } \\
\mathrm{R} \$ 0,56\end{array}$ & 22,10 & 50,40 \\
\hline
\end{tabular}

* USDA Nutrient Database for Standard Reference, 2001.

† Catálogo Sigma 2003/2004.

† Associação Paulista de Avicultura (APA): preço médio do ovo do tipo extra branco, no atacado, no mês de abril/2006, caixa com 30 dúzias, estado de São Paulo.

§ Agência Reuters (Folha de S. Paulo): dólar comercial a R \$2,281 em 06/06/2006. 


\section{M aterial e métodos}

\section{D elineamento experimental}

0 protocolo experimental deste estudo seguiu os princípios éticos na experimentação animal adotados pelo C olégio Brasileiro de Experimentação Animal e foi aprovado pela comissão de ética em experimentação animal da Faculdade de M edicina de Botucatu-U N ESP. 0 experimento foi realizado em 14 coelhos machos da raça $\mathrm{N}$ orfolk. $\mathrm{O}$ s animais foram recebidos no biotério de coelhos dos laboratórios experimentais com peso aproximado de $1.200 \mathrm{~g} \mathrm{e}$ idade aproximada de 80 dias. Para fins de adaptação, ganho de peso e al cance da idade ideal para o início do tratamento, os animais foram mantidos em gaiolas individuais com água ad libitum e ração comercial (N utricoelho, Purina ${ }^{\circledR}$ ) durante 14 dias, à temperatura eluz ambientes, além de o biotério ser equipado com sistema de ventilação e exaustão. Após esse período, os coelhos foram randomizados em dois grupos de sete animais: grupos $\mathrm{G} 1$ (controle) e $\mathrm{G} 2$ (com dieta suplementada com gema de ovo). Foram, então, alojados em gaiolas individuais numeradas e tatuados na orelha esquerda com as respectivas numerações das gaiolas, minimizando, assim, a possibilidade de extravio.

\section{Preparo da ração}

O sanimais do grupo $\mathrm{G} 2$ foram al imentados com dieta conten do uma gema de ovo acrescida de $13,5 \mathrm{ml}$ de óleo de milho para cada $150 \mathrm{~g}$ de ração comercial para coelhos (N utricoelho, Purina ${ }^{\circledR}$ ) por 3 meses. Esta dieta era preparada semanalmente, na quantia de $10 \mathrm{~kg}$ por vez, no dietário dos laboratórios experimentais da Faculdade de $M$ edicina de Botucatu. A ração comercial era moída em triturador e então misturada com as gemas de ovo, água eóleo de milho em equipamento batedor-misturador ( $\mathrm{M}$ arconi ${ }^{\circledR}$ ). A massa era submetida a peletização em picador de carne $\left(\mathrm{CAF}^{\circledR}\right.$, modelo 10 , ciclagem $60 \mathrm{H}$ z) e secada em estufa de secagem e esterilização (Fanem ${ }^{\circledR}$, modelo $320-\mathrm{SE}$ ) a $55^{\circ} \mathrm{C}$ por $24 \mathrm{~h}$. A ração foi conservada em equipamento de refrigeração até o consumo. Considerou-sequecadagema deovo continha $225 \mathrm{mg}$ de colesterol, 1,8 $\mathrm{g}$ de gorduras saturadas, 2,16 $\mathrm{g}$ de ácidos graxos monoinsaturados e 0,72 $\mathrm{g}$ de ácidos graxos poliinsaturados ${ }^{17}$. 0 G rupo $G 1$ recebeu ração habitual de mesma marca e lote pelo mesmo período de tempo, e a água foi oferecida ad libitum.
Controle de peso e dosagens bi oquímicas

O sanimais foram pesados mensalmente a partir do dia anterior ao início do tratamento. Após jejum de $14 \mathrm{~h}^{18}$, coletou-se sangue venoso da veia marginal da orelha direita em frascos de $6 \mathrm{ml}$ com anticoagulante para a dosagem do perfil lipídico. Foram coletadas amostras no tempo zero e ao final de cada mês de tratamento. Terminada a coleta, as amostras eram centrifugadasa $3.000 \mathrm{rpm}$ por $10 \mathrm{~min}$, easdosagensdos níveis plasmáticos de colesterol total, H D L-colesterol (H D L-c) e triglicérides eram real izadas no Laboratório de Bioquímica da Seção de Laboratórios de Análises Clínicas do Hospital das Clínicas da Faculdade de M edicinadeBotucatu-U N ESP pelo método dequímica seca em equipamento autoanalyzer (Johnson \& Johnson ${ }^{\circledR}$, modelo Vitros 950 ). O s valores da fração LDL-colesterol (LDL-c) foram obtidos por meio da fórmula de Friedewald ${ }^{18}$.

\section{Eutanásia}

O s coel hos foram anestesiados com o etil-1 metil-butil-barbiturato de sódio ( $\mathrm{N}$ embutal ${ }^{\circledR}$ ) por via intravenosa. Foram então tricotomizados desde a região cervical anterior até a eminência púbica e heparinizados ( $400 \mathrm{mg} / \mathrm{kg}$, IV ). A través de um acesso venoso, foram submetidos a eutanásia por excesso do mesmo anestésico.

\section{Avaliação macroscópica}

As aortas torácica eabdominal foram retiradas após toracotomia mediana, laparotomia mediana edissecção cuidadosa das artérias renais e da bifurcação ilíaca da aorta. Foi realizada a dissecção do pescoço, para a exposição das artérias carótidas em seu trajeto cervical, e retirada dessas artérias desde sua emergência na aorta. D issecou-se, ainda, o trígono femoral, isolando-se as artérias femorais. A pós a exérese das artérias em estudo, a gordura adventicial foi delicadamente removida. $\mathrm{A}$ aorta foi dividida nos seguintes segmentos: arco, aorta torácica, aorta abdominal eaorto-ilíaco. Esses segmentos, juntamente com as artérias carótidas e femorais, foram abertos em sua parede posterior, analisados em sua superfície luminal e então fixados em solução de formol tamponado a $10 \%$ por $24 \mathrm{~h}$. Posteriormente, foram corados em solução de Sudan IV (solução de $\mathrm{H}$ exheimer), padronizada por $\mathrm{H}$ olman et al. ${ }^{19}$. A pós a coloração, as superfícies luminais das artérias foram novamente inspecionadas, a olho nu e em microscópio 
para anatomia (D.F. Vasconcellos S.A. ${ }^{\circledR}$, São Paulo) em aumento de $10 \mathrm{x}$. Verificou-se a presença (áreas sudanofílicas) ou ausência (áreas não sudanofílicas) de placas ateroscleróticas, bem como a distribuição destas ao longo da luz vascular. 0 srins, fígado ecoração foram pesados em balança analítica (C hyo ${ }^{\circledR}$, JS-110; máx: $110 \mathrm{~g} / \mathrm{d}=0,0001 \mathrm{~g}$ ) e seccionados longitudinalmente para análise estrutural. 0 coração foi pesado após a abertura de suas câmaras para que se considerasse apenas sua estrutura, livre de sangue ou coágulos.

\section{Avaliação histopatológica}

Amostras das artérias e dos órgãos em estudo foram colocadas em frascos contendo solução deformol 10\%, para processamento em autotécnico (Leica ${ }^{\circledR}$, TP102) e montagem em blocos de parafina. Realizaram-secortes seriados de $5 \mu \mathrm{m}$ em micrótomo (Leica ${ }^{\circledR}, \mathrm{RM} 2155$ ) e coloração por hematoxilina-eosina (H E) e picrossírius. Com a $\mathrm{HE}$, obteve-se a morfologia geral da parede arterial e estrutural dos órgãos. 0 picrossírius visou a identificar espessamento fibroso da íntima. Foram retiradas amostras de todas as artérias em estudo, independente da formação de placas, e verificaramse as alterações gerais da parede vascular (processo inflamatório, integridade das lâminas elásticas, proporção de colágeno e fibras elásticas) e al terações por camadas da parede. As avaliações foram feitas por patologista sem conhecimento prévio dos grupos.

\section{Classificação das lesões encontradas}

As lesões ateroscleróticas encontradas no estudo macroscópico foram graduadas visualmente usando uma escala de $0-3^{20,21}$, segundo a quantidade de áreas sudanofílicas presentes na luz arterial $(0=$ ausência; 1 = discreta, restrita aos óstios; 2 = moderada; 3 =intensa). Somadas as informações macro e microscópicas, utilizou-se a classificação padronizada pelo comitê de lesões vasculares da American $\mathrm{H}$ eart Association ${ }^{22}$.

\section{Análise estatística}

As comparações entre os grupos foram feitas utilizando o teste de $M$ ann-W hitney. 0 s dados foram expressos em mediana com os quartis 25 e 75, e os resultados foram considerados estatisticamente significantes se $P<0,05$.

\section{Resultados}

\section{Variáveis corporais dos animais}

0 grupo que recebeu dieta suplementada teve peso corporal maior queo grupo controle $(P<0,001)$ ao final de 90 dias de seguimento. C om exceção do coração ( $P<0,05)$, os demais órgãos estudados não apresentaram diferença significativa quanto aos seus pesos ( $T$ abela 2 ).

T abela 2 - M ediana equartis do peso corporal edeórgãos viscerais soo final do experimento para os dois grupos

\begin{tabular}{lccc}
\hline Variáveis & $\begin{array}{c}\text { Controles (G 1) } \\
\mathbf{n = 7}\end{array}$ & $\begin{array}{c}\text { T ratados (G 2) } \\
\mathbf{n = 7}\end{array}$ & P \\
\hline Peso corporal final (g) & $3.430(3.290 ; 3.535)$ & $3.850(3.667,5 ; 3.950)$ & $<0,001^{* *}$ \\
Peso do fígado (g) & $117(112,4 ; 133,8)$ & $146(130,8 ; 164,8)$ & 0,072 \\
Peso do coração (g) & $7,55(7,31 ; 7,92)$ & $8,3(8,24 ; 8,96)$ & $<0,05 *$ \\
Peso dos rins (g) & & & \\
Direito & $9,04(8,72 ; 9,93)$ & $9,66(9,11 ; 10,47)$ & 0,259 \\
Esquerdo & $9,1(8,7 ; 10,14)$ & $9,58(9,13 ; 10,68)$ & 0,383 \\
\hline
\end{tabular}

Teste de Mann-Whitney.

$\mathrm{g}=$ gramas; $\mathrm{n}=$ números de animais por grupo. 
A

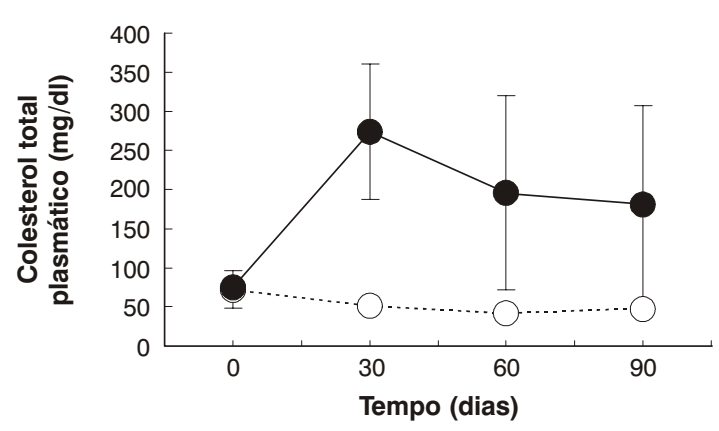

C

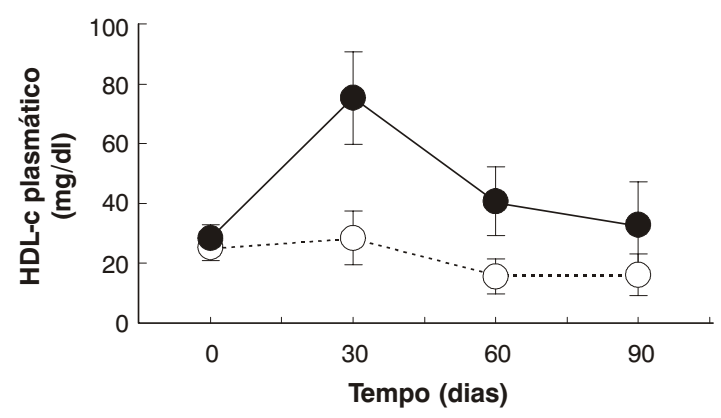

B

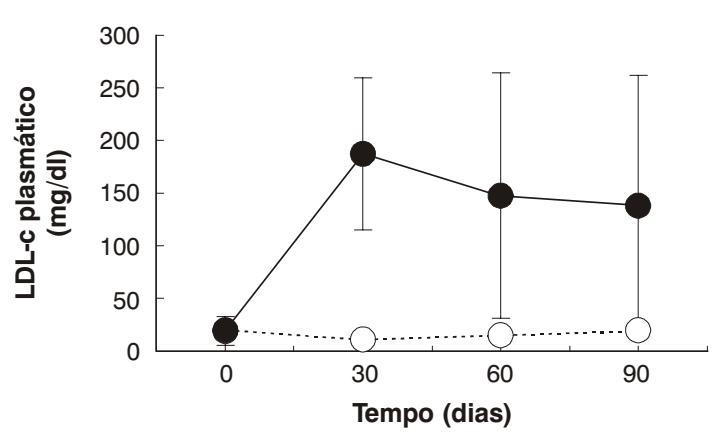

D

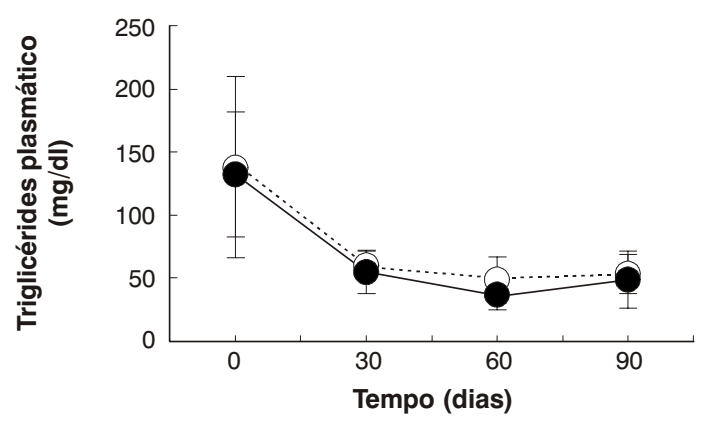

- Controles $\bigcirc$ Tratados (teste de Mann-Whitney)

${ }^{*} P<0,05 ;{ }^{*} P<0,001$.

Figura 1 - M édias e desvios padrão do perfil lipídico ( $\mathrm{mg} / \mathrm{dl}$ ) ao longo do estudo nos dois grupos experimentais. A) colesterol total; B) LD L-colesterol; C) H D L-colesterol; D ) triglicérides

\section{D osagens bioquímicas}

O sníveis plasmáticos de col esterol total, LD L-C, HDL-c e triglicérides estão descritos na Figura 1. $\mathrm{H}$ ouve aumento nas concentrações de colesterol total efrações no grupo que recebeu dieta suplementada com gema de ovo, porém não se observou diferença nos níveis de triglicérides entre os grupos.

\section{Avaliação macroscópica}

N ão se observou qualquer al teração macroscópica nos segmentos arteriais estudados dos animais do grupo controle, antes ou depois da histoquímica para gordura. Por outro lado, as artérias dos animais do grupo G2, depois da coloração, apresentaram áreas sudanofílicas correspondentes a lesões do tipo estrias gordurosas predominantemente na superfície luminal anterior do arco aórtico (Figura 2) e aorta abdominal (Figura 3 e Tabela 3).

\section{Análise histopatológica}

$\mathrm{N}$ ão foram encontradas alterações arquiteturais nas artérias de animais do grupo controle. $\mathrm{N}$ os animais que receberam gema de ovo, as al terações observadas concentravam-se na camada íntima e correspondiam a acúmulos lipídicos discretos no interior de células espumosas ou formando vacúolos subendoteliais (Figura 4). Essa alteração estava presente nas amostras de aorta abdominal (3/7), renais (2/7), 

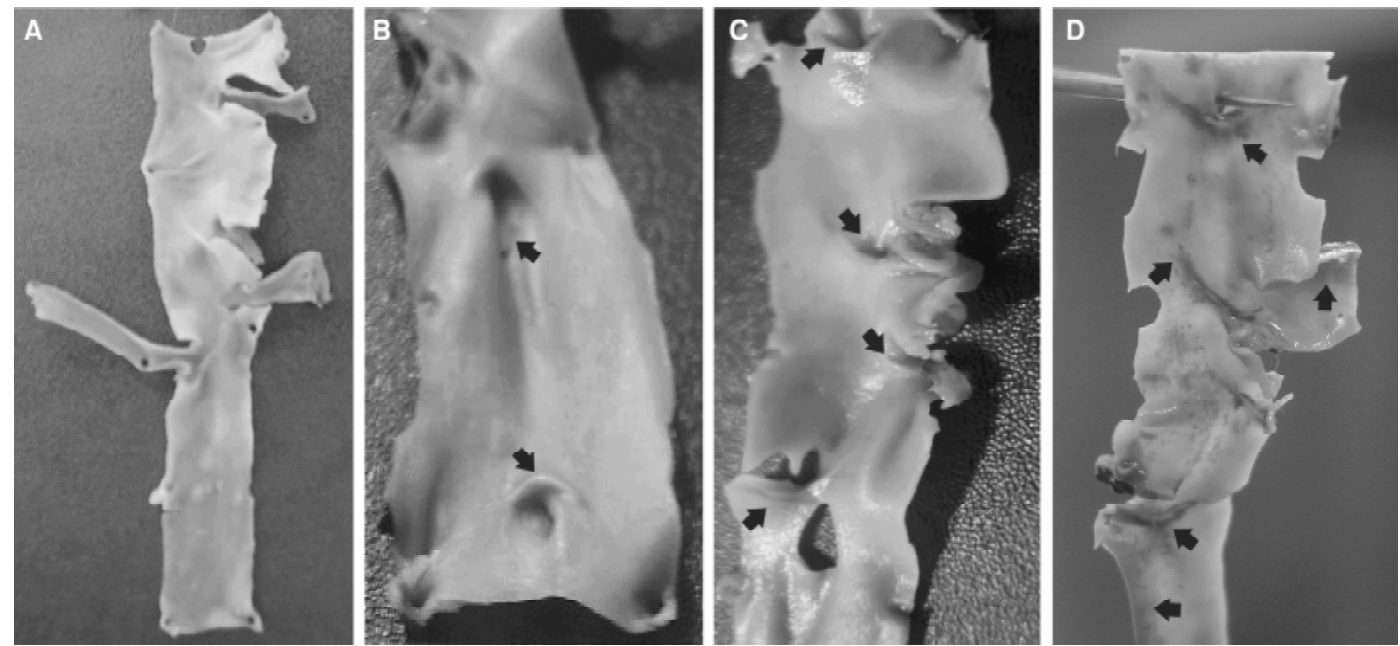

Figura 2 - Fotografia digital da superfície luminal anterior do arco aórtico aberto longitudinalmentee corado pel o Sudan IV em animaisquereceberam dieta hipercolesterolêmica. Asáreascoradas mais intensamente (setas) representam lesões ateroscleróticas. A) ausência de lesões (0); B) lesão discreta (1); C) lesão moderada (2); D ) lesão intensa (3)

carótidas (2/7), transição toracoabdominal (2/7) e femorais (2/7). Em apenas um animal, foi observado o espessamento de íntima em grau moderado, na transição toracoabdominal da aorta.

\section{D iscussão}

O smodelos experimentais são importantesferramentas para o estudo da aterosclerose e deram origem à maior parte dos conhecimentos atuais sobre sua etiologia, fisiopatologia e tratamento. A primeira investigação nutricional em aterosclerose coube a I gnatowski, entre 1908 e 1909. Acreditando que um metabólito tóxico da proteína animal levaria à aterosclerose, esse autor alimentou coel hos adultos com carne e coelhos recém- desmamados com leite e gema de ovo, obtendo aterosclerose em ambos. Stuckey, entre 1910 e 1911, observou que a gema de ovo era aterogênica e, em 1912, concluiu que havia um componente não-protéico na gema que funcionava como agente aterogênico. W esselkin, em 1913, tes-
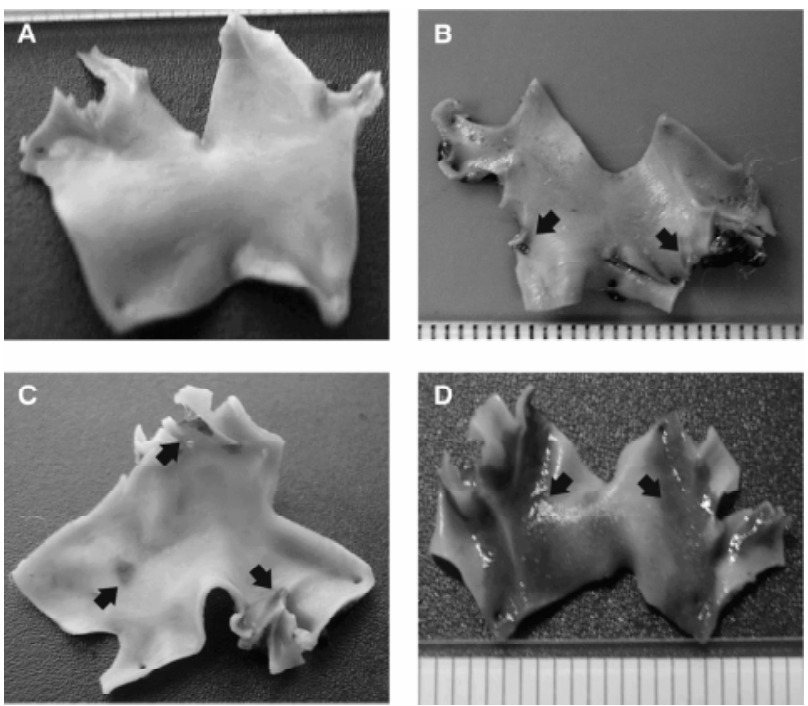

Figura 3 - Fotografias digitais da aorta abdominal, corada pelo Sudan IV, dos animais que receberam dietahipercolesterolêmica. Asáreascoradasmais intensamente (setas) representam lesões ateroscleróticas. A) ausente (0); B) discreta (1); C) moderada (2); D ) intensa (3) 
T abela 3 - Avaliação macroscópica e graduação* das áreas sudanofílicas nos segmentos aórticos e seus principais ramos em todos os animais do grupo tratado com gema de ovo

\begin{tabular}{lcccc}
\hline Artéria em estudo & \multicolumn{4}{c}{ Freqüência por tipo de lesão (\%) } \\
\cline { 2 - 5 } & $\mathbf{0}$ & $\mathbf{1}$ & $\mathbf{2}$ & $\mathbf{3}$ \\
\hline Aa. carótidas & $7 / 7(100)$ & - & - & - \\
Arco aórtico & $1 / 7(14)$ & $1 / 7(14)$ & $4 / 7(58)$ & $1 / 7(14)$ \\
Aorta torácica & $6 / 7(86)$ & - & $1 / 7(14)$ & - \\
Aorta abdominal & - & $3 / 7(43)$ & $3 / 7(43)$ & $1 / 7(14)$ \\
Aorto-ilíaca & $5 / 7(71)$ & $2 / 7(29)$ & - & - \\
Femorais & $7 / 7(100)$ & - & - & - \\
\hline
\end{tabular}

* Graduadas visualmente em uma escala de 0-3 ( 0 = ausência; $1=$ discreta, restrita aos óstios; 2 = moderada; 3 = intensa); G2 = grupo dos animais que receberam dieta hipercolesterolêmica; $\mathrm{n}=$ número de animais.

tou se o colesterol ou a lecitina poderiam ser o agente aterogênico do experimento de Stuckey. 0 bteve aterosclerose apenas nos coel hos alimentad os com gema de ovo e concluiu que o colesterol era o fator aterogênico presente na gema 23 .

O smodelos baseados na hipercolesterolemia induzida por via alimentar são os mais práticos edifundidos para 0 estudo da aterosclerose experimental ${ }^{11}$. 0 papel deste tipo de dieta na aterogênese é bem determinado. Lesões precursoras podem ser percebidas em apenas 1 semana de exposição à dieta hipercolesterolêmica24. Aikawa et al. mostraram que os lipídeos da dieta, provocando hipercolesterolemia, eram responsáveispor estresse oxidativo e lesão en dotelial na aorta de coel hos, deforma que apenas a redução lipídica na dieta reduzia os mecanismos lesivos à superfície arterial ${ }^{25}$.

Procurou-seestudar os efeitosaterogênicosdadieta em estudo da forma mais natural possível, ou seja, adotaram-se a via alimentar ad li bitum ea gema de ovo como fonte de colesterol. H ouve significativo aumento do peso dos animais que receberam ração suplementada. H ouve também aumento nas concentrações plasmáticas de colesterol total e frações no grupo que recebeu dieta suplementada com gema de ovo em relação aos controles. Esteaumento ocorreu demaneira expressiva nos primeiros 30 dias de oferta de ração suplementada, sendo que, nos momentos subseqüentes, houve queda inicial seguida de estabilização.
O s níveis de colesterol obtidos com dieta suplementada com $0,15 \%$ de colesterol proveniente da gema de ovo foram inferiores aos atingidos com a dieta padrão contendo $1 \%$ de colesterol purificado $12,13,15$. Por outro lado, houve comportamento temporal e valores de colesterolemia equivalentes aos de coelhos que receberam entre 0,1 e $0,25 \%$ decolesterol purificado por 60 dias $^{15}$. Ao comparar o aumento da colesterolemia entre as fontes de aterosclerose experimental, a gema de ovo foi menos efetiva que o ácido linoléico conjugado ${ }^{21}$. T ambém elevou menos a colesterolemia de coelhos que a caseína somada ao óleo de soja parcialmente hidrogenado por 6 meses $^{9,10}$, porém o menor tempo de exposição e o custo da fonte de material aterogênico respaldam o uso da gema de ovo. Por outro lado, a hiper-homocisteinemia étambém efetivo indutor de aterosclerose, mas sem interferir com o perfil lipídico do animal de experimentação ${ }^{26}$.

O s níveis plasmáticos de LD L-c e H D L-c ao final do experimento foram muito próximos daquele atingidospel o fornecimento de $0,1 \%$ decolesterol purificado por 60 dias ${ }^{15}$, denotando certa equivalência nos resultados obtidos. A gema de ovo pareceter sido ineficaz na elevação dos triglicérides plasmáticos, tal qual a dieta com colesterol purificado a $1 \%{ }^{13}$. A caseína somada ao óleo de soja parcialmentehidrogenado por 6 meses $^{9}$ eo ácido linoléico conjugado ${ }^{21}$ parecem ser mais efetivos na elevação desse parâmetro. 

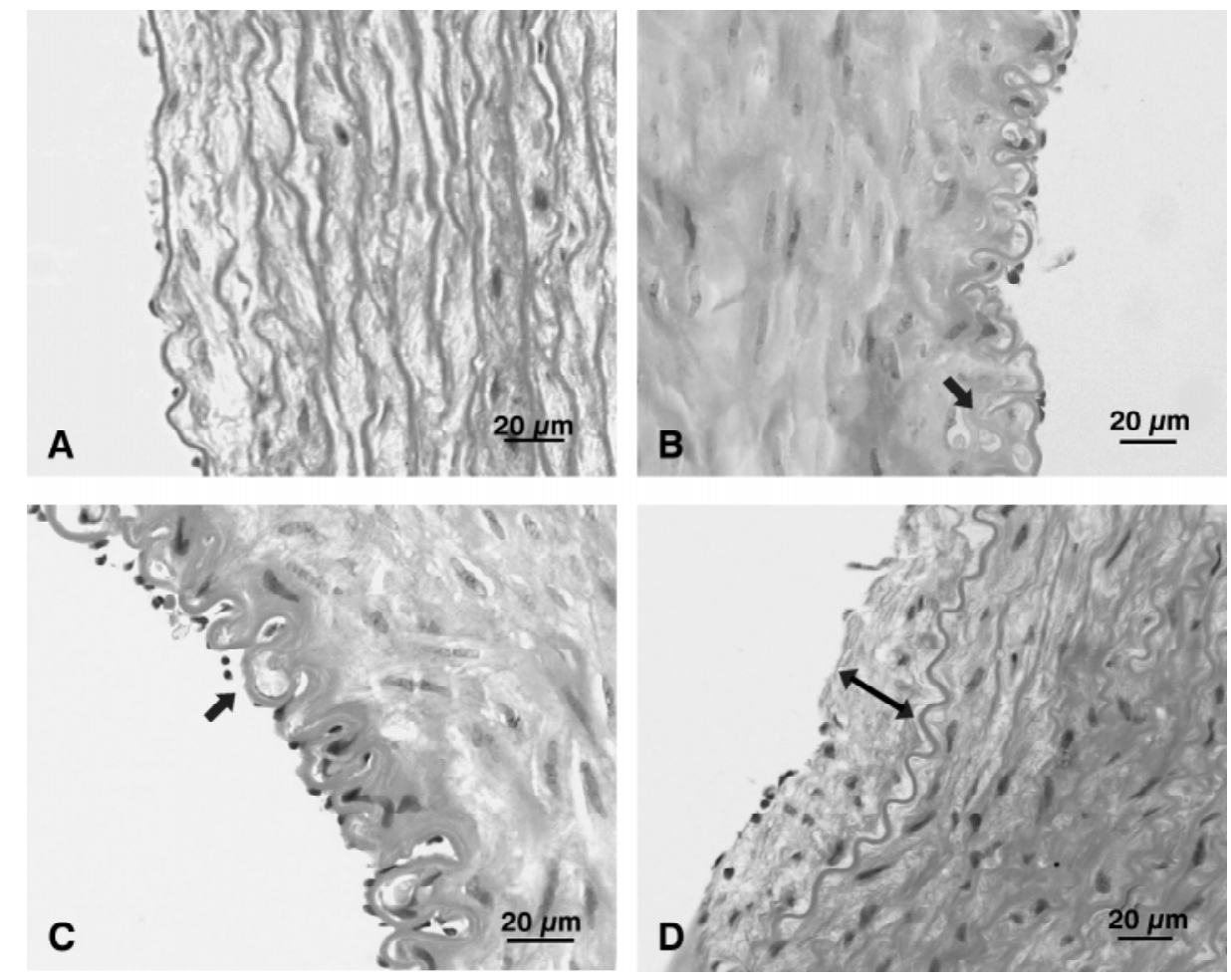

Figura 4 - Cortes transversais dos diferentes territórios arteriais estudados corados pela hematoxilina-eosina. O bservam-se alterações intimais compatíveis com aterosclerose. A) artéria de animal controle; B) observam-se células espumosas (imagens negativas) na aorta abdominal; C) artéria carótida comum; D ) notaseespessamento intimal na região detransição entreaortatorácica eabdominal

D estaque deve ser feito quanto à formação de lesões macroscópicas utilizando apenas a via al imentar de indução, reafirmando que a hipercolesterolemia é suficiente para a aterogênese. A maioria dos estudos que utilizam modelos experimentais em aterosclerose associa via alimentar e lesão mecânica da superfície endotelial ${ }^{15,27,28}$, fazendo com que a hipercolesterolemia seja o intensificador do processo, e não seu promotor. I sso porque, mesmo na ausência dehipercolesterolemia, há formação delesões ateroscleróticas nas artérias de-endotelializadas ${ }^{15}$.

Bocan et al. ${ }^{15}$ observaram que animais alimentados com dieta a 0,1 e 0,25\% de colesterol purificado desenvolveram lesões mínimas nas artérias que não sofreram denudação, e apenas níveis maiores que
0,5\% de colesterol alimentar provocaram estrias gordurosas, isoladas ou confluentes. Entretanto, o método proposto neste estudo evidenciou queépossível desenvolver tanto lesõesmicroscópicasmínimasquanto lesão do tipo estria gordurosa isolada em artérias com superfície endotelial preservada, mesmo com baixa proporção alimentar de colesterol. As lesões provocadas por este modelo experimental, por suas características macro e microscópicas, podem ser classificadas como tipos I e II da American H eart Association ${ }^{22}$, ou seja, são compatíveis com as alterações iniciais do processo aterosclerótico.

Este estudo foi proposto no intuito de viabilizar o amplo uso da aterosclerose experimental em investigações fisiopatológicas e terapêuticas. A dieta testa- 
da mostrou-se efetiva na indução de hipercolesterolemia no animal de experimentação, porém provocou apenas al terações iniciais do processo aterosclerótico. Por outro lado, pode-se considerar que a gema de ovo como fonte de colesterol alimentar a $0,15 \%$ provocou alterações arteriais e nos níveis plasmáticos de colesterol equivalentes àquelas provocadas pelo colesterol purificado comercial quando fornecido em baixa dosagem. D essa forma, abrem-se perspectivas para testar se maior oferta de gema de ovo diária desenvolveria lesões arteriais e colesterolemia mais expressivas, dados o baixo custo e a acessibilidade a essa fonte alimentar de colesterol. Em conclusão, a di eta com gema de ovo provocou ateroscleroseleveno animal deexperimentação ealterações equival entes àquelas provocadas pelo col esterol purificado comercial quando fornecido em baixa dosagem. Portanto, a gema de ovo pode ser utilizada como fonte de colesterol al imentar de baixo custo em modelos de aterosclerose experimental.

\section{Referências}

1. G ebara OCE, W ajngarten M, Barreto ACP. N ovos fatores de risco da doença arterial coronária. Rev Soc C ardiol Estado de São Paulo. 1997;7:340-7.

2. LuzPL, U int L. Endotélio na aterosclerose: interaçõescelulares e vasomotricidade. In: Luz PL, Laurindo FRM , Chagas ACP, editores. Endotélio e doenças cardiovasculares. São Paulo: Atheneu; 2003. p. 131-60.

3. Yoshida WB. O processo aterosclerótico: da disfunção endotelial à lesão complexa. In: Sitrângulo J r C, K auffman P, editor. D oença aterosclerótica periférica. São Paulo: BBS; 2004. p. 11-27.

4. $M$ ontenegro $M R G$. Patogenia da aterosclerose. In: M affei FH A, Lastória S, Yoshida W B, R ollo H A, editores. D oenças vasculares periféricas. Rio de Janeiro: Medsi; 2002. p. 999-1005.

5. Ross R. The pathogenesis of atherosclerosis: a perspective for the 1990s. N ature. 1993;362:801-9.

6. Ross R. Atherosclerosis- an inflammatory disease. N Eng J M ed. 1999;340:115-26.

7. Lastória S, M affei FH A. Aterosclerose obliterante periférica: epidemiologia, fisiopatologia, quadro clínico e diagnóstico. In: M affei FH A, LastóriaS, Yoshida W B, Rollo H A, editores. D oenças vasculares periféricas. Rio de Janei ro: M edsi; 2002. p. 1007-24.

8. Törnwall M E, V irtamo J, H aukka JK, Albanes D , H uttunen JK. Life-style factors and risk for abdominal aortic aneurysm in a cohort of Finnish male smokers. Epidemiology. 2001;12:94-100.
9. K ritchevsky D, T epper SA, D avidson LM , Fisher EA, K lurfeld D M . Experimental atherosclerosis in rabbits fed cholesterolfree diets. Atherosclerosis. 1989;75:123-7.

10. K ritchevsky D. D iet and atherosclerosis. J N utr H ealth Aging. 2001;5:155-9.

11. RamosM oralesEL. La aterosclerosis: algunas consideraciones acerca de su estudio experimental; revisión bibliográfica. Rev Cuba M ed. 1987;26:965-70.

12. Kolodgie FD, Petrov A, Virmani $R$, et al. Targeting of apoptotic macrophages and experimental atheroma with radiolabeled annexin $\mathrm{V}$ : a technique with potential for noninvasive imaging of vulnerable plaque. Circulation. 2003;108:3134-9.

13. Asai K, K uzuya M , N aito M , Funaki C, K uzuya F. Effects of splenectomy on serum lipidsand experimental atherosclerosis. Angiology. 1988;39:497-504.

14. Alfonso Valiente M A, Almeida Carralero G, Q uintela Pena $A M$, Simón Carballo R. Evaluación de un posible modelo experimental de aterosclerosis carotídea en conejos hipercolesterolémicos. Rev Cubana Invest Biomed. 2001;20:192-6.

15. Bocan TM, M ueller SB, M azur M J, U hlendorf PD, Brown $E Q$, Kieft KA. T herelationship between the degree of dietaryinduced hypercholesterolemiain therabbit and atherosclerotic lesion formation. Atherosclerosis. 1993;102:9-22.

16. Fernandes $A A H$, Alves MJQF, Boteon EM, Rosa GJM, $\mathrm{N}$ ovelli ELB. Avaliação do colesterol plasmático em coelhos com hipercolesterolemia induzida e tratados com extrato etanólico deprópolis. RevBrasPlantasM edicinais. 2002;4:1-5.

17. T abela de Composição Q uímica dos Alimentos. Disponível em: http://www.unifesp.br/dis/servicos/nutri/.

18. Bachorik, PS, Rifkind BM, Kwiterovich PO. Lipídios e deslipoproteinemias. In: $H$ enryJB, editor. D iagnósticosclínicos e tratamento por métodos laboratoriais. 2a ed. São Paulo: M anole; 1999. p. 208-36.

19. H olman RL, M cgill H C J r., Strong JP, G eer JC. T echnics for studying atherosclerotic lesions. Lab Invest. 1958;7:42-7.

20. D uff GL, M cM illan GC. The effect of alloxan diabetes on experimental atherosclerosis in rabbit. J Exper $\mathrm{Med}$. 1949;89:611-30.

21. K ritchevsky D, T epper SA, W right S, C zarnecki SK. Influence of graded level of conjugated linoleic acid (CLA) on experimental atherosclerosis in rabbits. N utr Res. 2002;22:1275-9.

22. Stary $\mathrm{HC}$. Thehistological classification of theatherosclerotic lesions in human coronary arteries. In: Fuster V, Ross R., T opol EJ, editors. Atherosclerosis and coronary artery disease. Philadel phia: Lippincott-Raven; 1996. p. 463-74.

23. K ritchevskyD . D ietary protein, cholesterol and atherosclerosis: a review of the early history. J N utr. 1995;125:589S-93S.

24. Ross R. The pathogenesis of atherosclerosis - an update. N Engl J M ed. 1986;314:488-500.

25. Aikawa M, Sugiyama S, H ill C C , et al. Lipid lowering reduces oxidative stress and endothelial cell activation in rabbit atheroma. Circulation. 2002;116:1390-6. 
26. Stahlke Jr. H S, França LH G, StahlkePH, Stahlke PS. H iperhomocisteinemia causando aterogênese na aorta de coelhos modelo experimental. J V asc Br. 2004;3:20-30.

27. Aikawa M , Rabkin E, O kada Y, et al. Lipid lowering by diet reducesmatrixmetalloproteinaseactivity and increasescollagen content of rabbit atheroma: a potential mechanism of lesion stabilization. Circulation. 1998;97:2433-44.

28. N ichollsSJ, C utri B, W orthley SG, et al. Impact of short-term administration of high-density lipoproteins and atorvastatin on atherosclerosis in rabbits. Arterioscler Thromb V asc Biol. 2005;25:2416-21.
Correspondência:

W inston Bonetti Yoshida

D epartamento de Cirurgia e O rtopedia

Faculdade de M edicina de Botucatu - UNESP

Campus Botucatu - D istrito de Rubião Jr., s/no

CEP 18618-000 - Botucatu, SP

Tel.: (14) 3811.6230, (11) 3811.6269

Fax: (14) 3815.3205

E-mail: winston@fmb.unesp.br

O conteúdo do J Vasc Bras está disponível em português e em inglês

no site do Jornal Vascular Brasileiro em

www.jvascbr.com.br 